\title{
Wanted: More Research
}

BY ETHEL M. FAIR

$\mathrm{T}$ HE PROSPECTIVE DOCTORAL STUDENT in librarianship does not lack for opportunity to pursue an investigation in virtually any field of our discipline." So states J. Periam Danton in a recent article. ${ }^{1}$

"Any field?" What are these fields available to the doctoral student in the existing library schools? College and university libraries, public libraries, bibliography, history of books and printing, or libraries as a social institution. Library work with children and young people, bibliographical history, technical processes, and reading and other media of communication. Library resources, organization of material for retrieval and use, personnel and training, historical evolution of libraries and of publications, comparative librarianship. These represent subjects offered by three library schools described by Danton from library school catalogs and correspondence.

The scope of the above list leaves something to be desired. The areas reflect too much the existing stereotypes of library operation. They fail to examine and cultivate the ground on which the library of today stands. They reflect too little demand for scholarly thinking and for new knowledge. Without deeper inquiry into underlying factors and more scholarly research, librarians will remain practitioners, will contribute little to the potentialities of the field and will fail to command the respect of scholarly disciplines.

Danton has presented a thorough study and a clear-cut exposition of the doctoral program in our library schools

1 "Doctoral Study in Librarianship in the United States, CRL, XX (1959), 435-453, 458.
Miss Fair, Director emeritus of the New Jersey College for Women Library School, is teaching at the Department of Library Science, University of Kentucky.

showing concisely the history of the program, its character, its products and the obstacles to greater participation in scholarly research in the profession. (It seems clear that "Doctoral study" in this article is synonymous with research and the production of new knowledge.)

One wishes that the author had gone farther and had shown the fundamental need for more research, especially for "pure" or basic research which underlies all practical application of new knowledge, and that he had pointed out the challenging areas and topics which wait to be explored. Retrospect in graduate study in librarianship is not enough.

Alan T. Waterman, director of National Science Foundation, describes this mental activity and its subsequent investigations as follows: "As a continuing search for new knowledge, basic research has certain characteristics which help us to distinguish it from other forms of scientific activity. The search is systematic, but without direction save that which the investigator himself gives it to meet the challenge of the unknown. . . . His work may be contrasted with that of scientists and engineers conducting applied research (laboratory studies concerning the practical use of newly found knowledge) or development, which takes applied research out of the laboratory and translates it into production." 2

2 National Science Foundation, Basic Research, a National Resource (Washington: Government Printing Office, 1957), p. 1. 
There is an apparent lack of recognition by librarians of the rainbow range of types of research, from the basic essential inquiry representing pure or basic research about which nobody asks, "And what is it good for?" through the additional steps in exploration to find out what it might be "good for," to the subsequent piece of applied technology which is derived from the findings of the pure research and creates a usable product, followed by the research needed to discover how to persuade the public to accept and use the new "invention."

To be sure, considerable so-called research, historical study or experimentation in techniques has been carried on in the library field which has had a practical application, as shown in Danton's article cited above. Other experiments have been carried out by library supply houses which have yielded improved operational procedures, some automation, and even gadgets-all of them "practical." All this is necessary and will continue as long as librarians are operation-minded. But it should be recognized that even this practical operation or gadget is derived from some previous creative thinking.

This spectrum of types of research is implied in Danton's analysis of dissertations for which doctor's degrees have been awarded. And the importance of basic research is recognized when Danton quotes William W. Brickman as saying: ". . . if the dissertation is to have any value at all there should be an allout effort to make its contribution to scholarship. The doctoral candidate should demonstrate a high order of ability to prosecute ... an intellectual problem in depth." 3

It is evident that the emphasis has been on the "practical" rather than on theory in graduate study in librarianship. We have neglected the deeper understanding of "what happens to people

3 Brickman, "Speed-up of the Ph.D. Degree," School and Society, LXXXVII (1959), 51-52. inside the library." 4 What can be done to raise the library as an authority on the character and history of society's records and of the reader's utilization of these records? How can we encourage more scholarly research? What can be done to open the doors to more serious investigation on all levels? What areas invite study? What assumptions are we now accepting without second thought? What levels of inquiry are called for in the topics which the field offers?

Some general areas of insufficiently explored conditions may be suggested: reader characteristics and behavior, subject contents of publications, sources of information or materials needed for research; literary style, and distribution of tax money.

Studies of reader behavior should go beyond the Madison Avenue surveys. They might not make any immediate recognizable difference in library operation but on the new knowledge gained it should be possible to design sounder reader service. Possible examples of subjects for study are:

Reader behavior as influenced by nationality, race, or religion.

Analysis of environmental pressures leading to or discouraging reading.

Student reading beyond the textbook in scientific fields vs. this type of reading in $(a)$ literature, $(b)$ religion, (c) fine arts, etc. ${ }^{5}$

Reader behavior of college freshmen, sophomores, juniors, and seniors analyzed and interpreted.

Reading in relation to mental health.

Analysis of reader behavior in a culture where reading material is scarce.

The reader-public of paperbacks $v s$. reader behavior toward (a) hard-cover

4"It is what happens to people inside the library that counts and not the yardage of catalog cards. . . [The library] is a diffusion center for the intellectual energy in the vital life of the mind." Norman Cousins, "The Library in the Modern World," CRL, XX $(1960), 455$. 5 This problem is treated in Jacob M. Price, Reading for Life (Ann Arbor: University of Michigan Press, 1959), chapters 5-7. 
publications, $(b)$ newspapers, $(c)$ magazines.

Subject content of publications has been too little analyzed. We have too little knowledge of the range and levels of subjects treated in publications of various types. This knowledge is fundamental to effective communication. To what extent has the new knowledge of space been given a form consumable by the "general reader"? Is there any difference in the subject content of publications coming from countries of different ideologies? Is there any relation between the discovered distribution of subjects in any given pertinent type of publication and the fields of knowledge of college curricula? To what extent are librarians responsible for coordinating the subject content of the library's collection with the curriculum and pupil requirements of the public education described in James Bryant Conant's report on American high schools, ${ }^{6}$ and what would this involve?

Some intensive studies ${ }^{7}$ are under way to discover much-needed information on materials used for research; but this is only a beginning. Such studies reach into backgrounds and subject fields and arrive at principles even though they may not represent pure theory. They look eventually toward practical application especially in the materials of applied science and technology and are particularly pertinent to current studies of obsolescence in library collections. Without the sound results of studies such as these, without the guidance of discovered fundamentals, present efforts to set standards for elimination of materials from collections must be highly experimental. Possible examples of studies in this area are: The lag in reducing new knowledge to communicable form for

- The American High School Today; A First Report to Interested Citizens (New York: McGraw-Hill, 1959)

7 See for example: Ralph R. Shaw. "The State of the Library Art," Library Journal, LXXXV (1960), 1337-1339. any specified reader-need, e.g. technical reports and scientific articles in foreign languages now being attempted by machines; variations in research needs in different scholarly fields. Case Institute of Technology is interested in content represented by "what chemists and physicists read, and why" 8 as basic to practical dissemination and use of scientific information. Massachusetts Institute of Technology is trying to determine the merit of items to be circulated measured by demand. ${ }^{2}$ The Operations Research Center ${ }^{10}$ of the Institute proposed to analyze and reduce the data and produce "the proper density of functions and cumulative distribution functions" to facilitate the study.

The fourth area of valuable inquiry is a measuring of literary style. While this may at first seem to be the domain of the student in literature, it should also be claimed by librarians as a foundation stone in their organized institution. What are the changes in literary style which reflect change in social and cultural patterns and are in turn reflected in the collections which libraries through generations have offered to readers? A study of symbolism as represented in collections of selected libraries is not without meaning to scholarship. Or, what is the relation of literary style to so-called popularity of publications? This does not imply a measuring of literary study; but it is desirable to know more about the essence of writings in the libraries of the world, to understand how the art infuses our collections.

Funds for the support of libraries and for research in the field will continue to come from tax sources and from foundations. What claim have libraries on such

\footnotetext{
8 Russell Ackoff, ["Information Requirements and Uses"] in National Science Foundation, Current Re search and Development in Scientific Documentation. No. 6 (Washington: Government Printing Office, 1960), p. 5 .

"Philip M. Morse, ["Information Requirements and Uses"] in National Science Foundation. Current Research and Development in Scientific Documentation, No. 6 . p. 10.

10 Ibid.
} 
monies? What can be offered to support these claims? How do the bases from such claims compare with those for distribution of tax money to other institutions? How are the responsibilities of the local, state and federal government related in the allotting of tax money to local institutions, - that is, basic political and economic principles of such division of responsibility? What is the basis of "fair share" in such distribution?

These five areas lie in what Lester E. Asheim has called the periphery of the reader and his books within which we work. ${ }^{10}$ They draw upon psychology, sociology and economics, to say nothing of literature. ${ }^{11}$ Scholarly inquiry is also increasingly needed in the area of internal organization of collections of society's records, i.e., in subject analysis, interpretation, classification and in the semantics of selected topic terms. The changes in today's world, like earth tremors, have jolted our old established schemes, outmoded subject headings and rigid notations. Research in this area must go back to theory, to principles, to analysis of existing and expanding knowledge, to a dissection of interrelated subjects and disciplines, and to identification of common elements. Some parts of all these aspects must be studied and the findings set forth before sound schemes of bibliographical control and information retrieval can be devised. Phyllis A. Richmond has presented some of the factors which enter into this study in her soundly analytical article on research in classification. ${ }^{12}$ David J. Haykin deplored the fact that "very little of objective experimentation is available on the general approach of the reader to the subject element of the dictionary catalog. . . . Even if the cataloger were to determine conclusively the mental processes of the

10 Speech at the Annual Conference of the American Library Association in Washington, D. C., June 1959. 11 Asheim, letter to the author, August 12, 1960.

12 "Some Aspects of Basic Research in Classification." Library Resources und Technical Services, IV (1960), 139-149. reader, he would still have to take account of linguistic problems." 13

The studies suggested might sometimes seem vague and elusive. They can become "increasingly divorced from deeds," in the words of August Heckscher, director of the Twentieth Century Fund. In the numerous investigations produced in doctoral programs in American universities, some sterile theses have been presented and have rightly been held up to ridicule. Grayson L. Kirk, in attacking the burden of the doctoral program, said: "Few dissertations do produce anything of value to the sum-total of human knowledge." ${ }^{14}$ Should pressure for Ph.D.'s in librarianship develop, there is no doubt but that some work will be inconsequential. But sound theory underlies sound practice. And blind alleys must be explored, if only to prove that they lead nowhere. In some unexpected corners the foundation of future solid building will be found.

The obstacles to the pursuit of research mentioned by Danton are all too true: lack of financial support, length of time required to obtain the degree, indifference of the practicing librarian to problems which call for academic exploration, lack of incentive in steps of professional advancement, and little demand for the doctor's degree from the public or special library and even less, he says, from the school library. Also included are lack of time in the demanding schedule of the library and in the call for "more practical training." These obstacles have been accepted and enlarged upon by outstanding librarians in the country, as quoted in the Danton article.

It should be noted that most of these hurdles exist also in other disciplines in which opportunities for doctor's degrees are offered. Doctoral candidates in all departments of knowledge have struggled

\footnotetext{
13 Subject Headings, a Practical Guide (Washington, D. C.: Government Printing Office, 1951), p. 4-5.

is From address at the University of North Dakota, November, 1958, quoted by Brickman, loc. cit.
} 
with penury, discouragement, and delayed awards. Danton says: “. . . the figure [of doctor's degrees granted in librarianship] is not in unfavorable contrast with those for certain of the other newer professions ..."15 such as forestry, architecture, journalism, meteorology, public administration and social work. In the emerging pattern of institutional organization and management the emphasis on the practical is natural. The conditions inherent in librarianship are described by Jesse H. Shera when he writes: "Of all the forms of education, library professional education is perhaps the most inherently paradoxical, for it is at once important and trivial . . . librarians have focused their attention upon their technology, they have failed to see the deeper meaning of what they do, and hence have been unable to raise their activities to the level of a true profession." 16 The inescapable routines required to keep the institution running exist side by side with the thesis that the library "is a diffusion center for the intellectual exercises in the vital life of the mind." 17

The existing graduate library schools of the world are the principal agencies through which scholarly inquiry can be achieved. They have an obligation; indeed their justification lies in their ability to foster such inquiries. That they are victims of the obstacles to pure or basic research mentioned above and that they have had to yield to pressure from

\footnotetext{
15 Op. cit., p. 438

10 "Theory and Technique in Library Education," Library Journal, LXXXV (1960), 1736, 1738. 17 Cousins, op. cit., p. 455.
}

practicing librarians to emphasize the "practical" subjects in doctoral dissertations can be seen from Danton's analysis of dissertation titles and from the listings in Library Research in Progress. ${ }^{18}$ Until the professon at large has a better recognition of the importance of research including basic research and until there is greater demand for personnel who have contributed to scholarly inquiry, the emphasis in the studies will be mainly on historical narrative and applied operations. Within the profession there must be sufficient recognition of the importance of study of the history and contents of books, the reader and his compulsion to read, the relation of the library to the dissemination of ideas, the social history of the library as an institution, the classification of knowledge, bibliography as a mirror of cultures and as a servant of research, and the operation of libraries in today's society, before library schools can give intensive encouragement to scholarly research. The demand must come from the profession as part of its claim to scholarship. Only when librarianship can offer a substantial body of sound research on various levels or in various types in the spectrum of serious inquiry can it produce underlying principles on which to develop better practices or add new knowledge by which it will enrich librarianship as an exponent of today's culture and through which it may be viewed as a liberal discipline rather than as a field of applied technology.

18 U. S. Office of Education. Library Services Branch. Library Research in Progress (Washington, 1959. ). 